alone. Four weeks later she was discharged from hospital taking 62 IU daily. The chloroquine dose was gradually reduced, and she remained responsive to subcutaneous insulin.

The rarity of true subcutaneous insulin resistance has been emphasised. ${ }^{3}$ The patient reported on by Blazar et al had accelerated insulin degradation in subcutaneous fat but also showed severe resistance to intravenous insulin. ${ }^{2}$ There is evidence that, in addition to its action on hepatocyte receptors and receptor mediated degradation, chloroquine also inhibits lysosomal degradation in human skeletal muscle ${ }^{4}$ and fibroblasts ${ }^{5}$ and that it inhibits adipocyte insulin degradation in vivo. ${ }^{6}$ Chloroquine's action may help to explain the pathogenesis of this rare syndrome as well as being useful in its management.

RICHARD G REES

Department of Rheumatology,

Westminster Hospital

London SW1P 2AP

MichaEL J SMITH

Royal Surrey County Hospital,

Guildford,

Surrey GU2 5XX

1 Campbell IW, Kritz H, Najemnik C, et al. Treatment of type I diabetic with subcutaneous insulin resistance by a totally implantable insulin infusion device (Infusaid). Diabetes Research 1984;1:83-8.

2 Blazar BR, Whitley CB, Kitabchi AE, et al. In vivo chloroquine induced inhibition of insulin degradation in a diabetic patient with severe insulin resistance. Diabetes 1984;33:1133-7.

3 Schade DS, Duckworth MD. In search of the subcutaneousinsulin-resistance syndrome. $N$ Engl f Med 1986;315:147-53.

insulin-resistance syndrome. $N$ Engl $\mathcal{G}$ Med 1986;315:147-53.
Neal GW, Kitabchi AE. Insulin degradation by human skeletal muscle. Biochim Biophys Acta 1982;719:259-66.
mil

5 Harris HL, Stentz FB, Kitabchi AE. Fibroblast degradation of human insulin: role of neutral and acid proteases in insulin degradation activity. Diabetes 1981;30(suppl 1):524.

6 Duckworth WC, Kitabchi AE. Insulin metabolism and degradation. Endocr Rev 1981;2:210-33.

SIR,-Dr G D Smith and colleagues (21 February, p 465) conclude that chloroquine may have a role in reducing postprandial hyperglycaemia in noninsulin dependent diabetic patients by decreasing insulin degradation. This potentially exciting finding needs to be qualified as, firstly, the pathophysiology of non-insulin dependent diabetes is heterogenous and increased exposure of peripheral tissues to insulin in some patients may exacerbate insulin resistance, ${ }^{1}$ and, secondly, the use of changes in plasma $\mathrm{C}$ peptide and insulin concentrations to measure insulin secretion and hepatic extraction, particularly in the non-steady state after ingestion of oral glucose, is questionable because of the large individual variability in $\mathrm{C}$ peptide and insulin concentrations. ${ }^{2}$

There are now non-invasive techniques for assessing these variables. We suggest that such techniques should be used to assess the mechanisms of action, and consequently the role, of chloroquine in improving glucose tolerance in patients with non-insulin dependent diabetes mellitus.

Alan Peiris AHMED H KisSEBAH

Medical College of Wisconsin,

Milwaukee,

Wisconsin 53226

1 Reaven GM. Insulin secretion and insulin action in non-insulindependent diabetes mellitus: which defect is primary? Diabetes Care 1984;7:17-24.

2 Peiris AN, Mueller RA, Smith GA, Struve MF, Kissebah AH. Splanchnic insulin metabolism in obesity: influence of body fat distribution. F Clin Invest 1986;78:1648-57.

\section{Alcohol and violence}

SIR,-The management of patients who claim to have been assaulted is an accepted part of the workload of every accident and emergency depart- ment. Increased violence is now expected every weekend, over the New Year in Scotland, and after football matches throughout Britain.

Our department enjoys a suburban setting and has perhaps been shielded from the violence witnessed by some inner city departments. Nevertheless, analysis of the number of patients who have been assaulted coming into the department over the past year shows an increase of large scale violent incidents. Between $2 \%$ and $5 \%$ of our patients who have been injured in accidents claim to have been assaulted (the true figure is probably higher), but around New Year the incidence increased dramatically.

Between midnight and 8 am on New Year's Day we saw 59 patients. Of these, 45 had sustained recent injury, and $24(53 \%)$ of these claimed to have been assaulted, five having received human bites. All of the injured patients were intoxicated Excessive alcohol consumption also precipitated the attendance of three of the "medical" cases (an epileptic, a diabetic, and a haemophiliac). Throughout the night the department was full of policemen and drunken people supporting their injured friends.

Some departments may accept this problem and others may as yet have no experience of it. Certainly, most senior doctors and senior policemen do not learn about it until the next day, and the general public views the subsequently published statistics with distant apprehension The link with alcohol, so obvious to those of junior rank, who usually treat the patients, is rarely emphasised.

The only effective influence on alcohol consumption is cost. As Sir George Godber (24 January, p 245) pointed out, if the government really is concerned about public law and order it could show its conviction and be guaranteed success by increasing the tax on alcohol. Perhaps the budget surplus could then be used to finance the health service.

Hope Hospital,

D W YATES

H CHAMBERS

\section{Effect of dietary cholesterol on plasma cholesterol concentration}

SIR,-The report by Ms Jacqueline Edington and coworkers ( 7 February, p 333) is a fine example of the degree of precision that can be obtained in nutritional studies even in free living populations. An important conclusion is that reducing dietary cholesterol offers little benefit if the diet is already low in saturated fats. This implies that people need not avoid cholesterol rich foods, such as eggs, provided they have reduced their intake of saturated fats and increased that of polyunsaturated fats. This is one possible interpretation of the data.

A close examination of the results suggests that the conclusion on which they have made those interpretations can be questioned. Their study compared, in a crossover design, the effects on the serum cholesterol concentration of adding eithe seven eggs weekly (high cholesterol) or two eggs weekly (low cholesterol) to a prudent diet. Each crossover period lasted four weeks. The authors concluded that the serum cholesterol concentration was lowered significantly with the low cholesterol diet for the first four weeks but not at the end of the eight week study. The total cholesterol concentrations for the entire group were as follows: basic diet $5.70 \mathrm{mmol} / 1$; high cholesterol period $5.57 \mathrm{mmol} / \mathrm{l}$ after four weeks and $5.57 \mathrm{mmol} / \mathrm{l}$ after eight weeks; low cholesterol period $5.43 \mathrm{mmol} / \mathrm{l}$ after four weeks and $5.46 \mathrm{mmol} / \mathrm{l}$ after eight weeks. These data are remarkably consistent, but only the difference between the two four week dietary periods is significant. Clearly, however, the difference at eight weeks was virtually the same as at four weeks and may not have reached significance because the overall differences were small.

The important questions are, firstly, whether the difference observed is important in relation to the whole community and, secondly, whether that difference can be ignored, as suggested by the authors. The actual difference was a $2 \cdot 5 \%$ reduction in the serum cholesterol concentration. On the basis of most published prospective data and data on cholesterol lowering intervention, this fall in serum cholesterol concentration would be reflected in at least a $5 \%$ reduction in new clinical coronary artery disease events-in my view, a substantial benefit. Their interpretation can also be challenged on the grounds that not all individuals would make the necessary effort to lower saturated fat and increase the polyunsaturated to saturated fat ratio in their diets. The authors are correct in drawing attention to the effect of the interaction between dietary cholesterol and dietary fatty acids on the serum cholesterol concentration. An equivalent intake of cholesterol raises the serum cholesterol concentration more in those who have a high intake of saturated fatty acids than in those with a lower intake. Therefore, if the dietary modification of fatty acid intake were less the benefit of lowering cholesterol intake would be greater than that achieved in this study. This benefit might well apply to individuals in the community who would prefer to reduce their consumption of cholesterol rich foods than to make major cuts in their intake of saturated fat. Though I agree with the authors that the best public health approach is to emphasise a reduction in the intake of saturated fatty acids, they may have understated the additional value of also lowering cholesterol intake for the whole community.

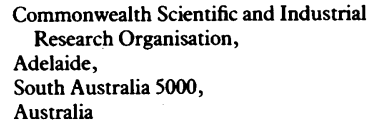

P J Nestel

\section{Better reporting of adverse drug reactions}

SIR,-Dr Frank Wells, medical director of the Association of the British Pharmaceutical Industry (14 March, $p$ 704), raises important issues concerning the reporting of adverse drug reactions and will be discussed by the Committee on Safety of Medicines at the earliest opportunity.

As Dr Wells states, the Department of Health and Social Security (and indeed the Committee on Safety of Medicines) has always insisted that the reporting doctor should remain anonymous when details of adverse drug reactions are passed to pharmaceutical companies. He did not state the reason for this policy-namely, the concern that the reporting doctor would be subject to harassment by the company. This concern is also shared by the director of the association, Dr J P Griffin, who stated at a public meeting last year: "I wish I had no worries about the kind of correspondence that goes from companies to doctors. I agree that probably nine out of every 10 , or perhaps 99 out of every 100 , adverse drug reaction follow up letters are acceptable, but, within the last three months, I have had complaints from physicians, giving me letters that have been sent to them from member companies which have been harassing them. Harassment does occur. We are fooling ourselves if we believe that it does not."

The spontaneous reporting of adverse drug reactions ultimately depends on mutual trust between the reporting doctor and the recipient of 
the information. If this relationship is undermined by the type of behaviour described by Dr Griffin it is difficult to see the advantages of disclosing doctors' identities.

The department's medical staff do follow up a number of reports, and this is done with due regard for the pressures on reporting doctors and the complex confidentiality and legal issues inherent in adverse reaction reporting.

G JONES

Committee on Safety of Medicines,

Department of Health and Social Security, London SW8 5NG

1 Mann RD. Adoerse drug reactions. London: Parthenon Publishing (in press).

\section{Adverse reaction monitoring using cohort identification}

SIR,-We agree with Dr J P Griffin (28 February, p 576) that the sensitivity of prescription event monitoring using cohorts of up to 20000 patients may not be sufficient to detect adverse reactions that occur at a frequency of less than one per 1000 . The numbers of patients followed up by such monitoring are determined not by the system itself but by the number of questionnaires doctors are prepared to complete.

Dr Griffin proposes a scheme of cohort identification for all new drugs marketed in general practice. As with prescription event monitoring, cohorts of up to 100000 patients would be identified and used, retrospectively, only if it became necessary to test a hypothesis about specific adverse reactions. We have been doing precisely this for a limited number of drugs since 1981 . In addition to 19 standard prescription event monitoring studies we have stored the details of large cohorts of patients treated with eight other drugs. Thus more than 700000 prescriptions have been stored in case a serious problem requires investigation later.

Unfortunately, banking large cohorts of patients is not as simple or inexpensive as Dr Griffin suggests. When an established drug is used on a very large scale a cohort of users may be identified by collecting prescriptions for the whole country during a short period, with each prescription identifying a single patient. (If prescriptions are collected for longer periods most are repeats.)

Few drugs rapidly achieve use by as many as 100000 patients. For example, a drug that is prescribed monthly for a chronic disease usually achieves sales equivalent to the addition of 20000 new patients during each of the first five years of marketing, and thus more than three million prescriptions would have to be collected to identify 100000 patients. The Prescription Pricing Authority cannot include the patient's name or address on computer record, and we estimate that 45 operator years of work by our experienced clerks would be required to process three million prescriptions even before questionnaires could be sent to doctors. If all doctors returned their questionnaires we would expect to find that about 30000 patients had moved to a new practice and if the drug was a non-steroidal anti-inflammatory or hypotensive one that about 15000 had died by the time 100000 patients had been assembled.

We have used prescription event monitoring on several occasions and have achieved response rates exceeding $75 \%$. It would be wasteful to duplicate the procedure for collecting prescriptions, which is already conducted for all new drugs during the first few years of marketing. A case could be made, howivever, for taking a 100000 patient sample as soon as sales reached the point when a one patient, one prescription sample was possible. The Drug
Safety Research Unit could store these samples and launch an investigation whenever the Committee on Safety of Medicines requested one.

Measured by its ability to collect large cohorts of patients treated with any one drug, prescription event monitoring is already 10 times larger than any other scheme in the world. It is entirely complementary to the yellow card scheme, and it seems very unlikely that either will be replaced by record linkage schemes, however desirable this might be in the distant future. The only barrier to the expansion of such monitoring is the workload on the Prescription Pricing Authority and general practitioners.

Drug Safety Research Unit,

WILLIAM H W INMAN Southampton $\mathrm{SO} 32 \mathrm{BX}$

Nigel S B RaWSON

Father fails in attempt to stop girlfriend's abortion

SIR,-Your legal correspondent rightly reported the appeal court judges' astonishment that Oxfordshire Health Authority would not proceed with the termination of pregnancy in this very sad and difficult case until a decision of the House of Lords was known ( 7 March, p 631). However, not all the facts were available to the court when the judges expressed that view.

The health authority's officers had been told that, should the appeal fail, means had already been found that (should leave to appeal be granted) the case would be heard in the House of Lords the next day. This information was not available to the Appeal Court judges when they expressed surprise. The authority's officers were simply trying to act as best they could in difficult circumstances in seeing that medical staff were advised of the legal position and were not rushed into taking decisions that they might feel required further discussion with the patient.

In the end, it is surely the doctor-patient relationship and not the speed of reaction to decisions of the court that should govern what is done, and when, in such a difficult situation-as happened in this particular case.

C H PaINe

Oxfordshire Health Authority,

Headington,

Oxford OX3 9DZ

\section{Neuropathy of the feet due to running on cold} surfaces

SIR,-Mr M Reichl's report (7 February, p 348) highlights once again the public's ignorance of the potential dangers of the cold. Even hardy and fit karate exponents are not impervious to its effects.

The distribution of the skin injury in the illustrated example certainly suggests that the blisters corresponded to the weight bearing surfaces of the feet. As no pain was experienced during running a cold induced local peripheral neuropathy, rather than the direct effects of the cold, presumably contributed to the development of blisters. The description of "bright red soles" implies rewarming hyperaemic vasodilatation, which suggests that a cold thermal injury had been inflicted, and this might have compounded the blistering in addition to blocking nerve conduction.

The report does not refer to the wind chill factor. Running at a speed of $16 \mathrm{~km} / \mathrm{h}$ would effectively lower the reported ambient air temperature of $-5^{\circ} \mathrm{C}$ to $-14^{\circ} \mathrm{C}$. Any prevailing wind would have further reduced the effective environmental temperature to even more dangerous levels.
Few risk factors for the development of local cold injury have been identified,' and several questions arise from $\mathrm{Mr}$ Reichl's report. What features made the 25 casualties more susceptible than the 135 who did not report sick? Did any runners of Negro origin (a high risk group ${ }^{2}$ ) compete, and if so how did they fare? Were the sufferers the slower runners, whose injuries occurred because of prolonged contact with cold surfaces, or were they the faster runners, who would have created a greater wind chill factor and friction? Did the patients experience severe paraesthesia on rewarming, a constant feature of non-freezing cold injury?

The real message of $\mathrm{Mr}$ Reichl's report is the need to educate the public in the potentially damaging effects of even brief exposure to the less than extreme temperatures of a British winter.

T R WHELAN R P CRAIG

Department of Surgery,

British Military Hospital,

Rinteln,

West Germany

Craig RP. Military cold injury during the war in the Falkland Islands 1982: an evaluation of possible risk factors. $\mathcal{J} R A r m y$ Med Corps 1984;130:89-96.

2 Miller D, Bjornson DR. An investigation of cold injured soldiers in Alaska. Milit Med 1962;127:247-52.

Future of the pathologist in an era of technological change and cost containment

SIR,-Dr G W Pennington (21 February, p 521) has highlighted the increased pressure on laboratory budgets engendered by the current cost cutting climate in the National Health Service. One part of the laboratory budget that attracts a disproportionate amount of attention is the on call service, as it is widely believed to be abused. Furthermore, the additional labour costs of on call work are easily identified, and it is often assumed that if the amount of work could be reduced expenditure would decrease proportionately.

We tested this by examining the 467 analytical requests relating to patients at this hospital that were sent out of hours to the clinical chemistry department over 18 days, which included three weekends. The notes for these patients were examined to ascertain the reasons for making the request. A request was considered justified if it could be shown that, in view of the clinical circumstances when the request was made, there was a reasonable chance that the results of the investigation would show or exclude a clinically important abnormality requiring action.

We determined the financial consequences of reducing requests by examining the laboratory on call records. The regulations governing payment for on call work mean that there is no financial saving unless all requests in a call period are eliminated. At this busy district general hospital a mean of 2.5 requests were dealt with during each call period, and thus each request attracted an on call labour cost (including standby) of $£ 4.01$. We then calculated the effect on the on call budget of two strategies. The first eliminated all requests that we considered to be unjustified or that could have waited until the next working day. This resulted in a $16 \%$ reduction in requests but only a $4 \cdot 6 \%$ reduction in on call labour costs. With the second strategy all routine monitoring, preoperative, or screening investigations were eliminated. This decreased the workload by $44 \%$ but reduced on call labour costs by only $18 \%$, with the cost of each request rising to $£ 5 \cdot 90$.

We have shown that there is little abuse of the out of hours laboratory service at this hospital and conclude that reductions in the on call workload 